\title{
Immunoglobulin E associated respiratory diseases: Part 2
}

\author{
Amr Ismail MD, Kenneth C. Iwuji MD, James A. Tarbox MD
}

\begin{abstract}
Multiple pulmonary pathologies have been associated with elevated levels of Immunoglobulin E (IgE). Since its discovery in 1966, its role in multiple diseases has become clearer. This has allowed for the emergence of new medications that target IgE. In this review, we will summarize some of the most common pulmonary pathologies in which IgE has a role in their etiology.
\end{abstract}

Keywords: Immunoglobulin E, asthma, allergic rhinitis, acute eosinophilic pneumonia, chronic eosinophilic pneumonia, parasitic lung infection, allergic bronchopulmonary aspergillosis

\section{INTRODUCTION}

Immunoglobulin $\mathrm{E}(\lg E)$ is one of the five human immunoglobulins: $\lg G$, $\lg A$, $\lg M, \lg D$, and $\lg E$. It is produced by $B$-cells after they undergo isotype switching to produce IgE instead of the default IgM. This is usually achieved by DNA recombination events within the immunoglobulin heavy chain locus. B-cells produced in the bone marrow produce heavy chains for both $\operatorname{lgM}$ and $\operatorname{lgD}$. Later in the B-cell life cycle, after stimulation by specific cytokines and T-cell interaction, the $\mathrm{B}$-cell undergoes class-switch recombination and can produce different immunoglobulin classes, including $\operatorname{lgE}{ }^{1}$

The role of IgE in humans is not fully understood. It is the least abundant isotype in the serum and has the shortest serum half-life ( 2 days) among human immunoglobulin types. ${ }^{2}$ It has an obvious role in defense against parasitic infections and inactivation of certain venoms. It also has a major role in the process of immune regulation and, therefore, is involved in the pathogenesis of allergic disease. ${ }^{1} \lg \mathrm{E}$ exerts

Corresponding author: Amr Ismail Contact Information: Amr.ismail@ttuhsc.edu DOI: 10.12746/swrccc.v7i31.593 these effects by its dual interactions with specific antigens and two receptors, FceRI and CD23, present on effector cells, most notably mast cells, basophils, eosinophils, and monocytes.

In this review $\bullet$, we will summarize some of the most common pulmonary pathologies in which $\lg E$ has a role in their etiology (Table 1).

\section{Asthma}

Asthma, according to the National Asthma Education and Prevention Program, is defined as a chronic inflammatory disorder of the airways in which many cells and cellular elements have a role; these include mast cells, eosinophils, neutrophils (especially in sudden onset, fatal exacerbations, occupational asthma, and patients who smoke), T lymphocytes, macrophages, and epithelial cells. In susceptible individuals, this inflammation causes recurrent episodes of wheezing, breathlessness, chest tightness, and coughing, particularly at night or in the early morning. These episodes are associated with widespread

- Part 1 of this review was published in July 2019 in The Southwest Respiratory and Critical Care Chronicles 2019;7(31):29-35. 
Table 1. Summary of IgE related pulmonary conditions

\begin{tabular}{|c|c|c|c|}
\hline Disease & Characteristics & Diagnosis & Treatment \\
\hline Asthma & $\begin{array}{l}\text { Chronic inflammatory } \\
\text { disorder of the airways } \\
\text { Episodic wheezing, chest } \\
\text { tightness, SOB, and cough } \\
\text { Airflow limitation is the } \\
\text { hallmark of the disease }\end{array}$ & $\begin{array}{l}\text { Suggestive history and } \\
\text { symptoms } \\
\text { Reduced FEV1 and } \\
\text { reduced FEV1/FVC } \\
\text { Reversibility is positive } \\
\text { when FEV1 (or FVC) } \\
\text { increase } \geq 12 \% \text { or }>200 \mathrm{ml} \\
\text { after bronchodilator }\end{array}$ & $\begin{array}{l}\text { SABA are used for mild symptoms } \\
\text { Inhaled corticosteroids and LABA } \\
\text { are added for maintenance therapy } \\
\text { Other medications: leukotriene } \\
\text { receptor antagonists, long-acting } \\
\text { muscarinic receptor antagonists, } \\
\text { and biologics (anti-IgE, anti-IL-5, } \\
\text { anti-IL-5R } \alpha \text {, and anti-IL-4 } \alpha \text { ) } \\
\text { Allergen immunotherapy is used } \\
\text { when a strong association with } \\
\text { allergens exists }\end{array}$ \\
\hline Allergic rhinitis & $\begin{array}{l}\text { Chronic inflammatory } \\
\text { disorder of the nasal mucosa } \\
\text { Associated with } \\
\text { rhinosinusitis, allergic } \\
\text { conjunctivitis, and asthma } \\
\text { Congestion, rhinorrhea, } \\
\text { sneezing, itching, upper } \\
\text { airway obstruction, and } \\
\text { watery eyes are common }\end{array}$ & $\begin{array}{l}\text { Chronicity, seasonality, } \\
\text { and pattern of symptoms } \\
\text { suggest diagnosis } \\
\text { Pale, boggy nasal } \\
\text { turbinates; nasal crease; } \\
\text { allergic shiners }\end{array}$ & $\begin{array}{l}\text { Mild/episodic symptoms are } \\
\text { treated with second-generation } \\
\text { antihistamines } \\
\text { Moderate/severe symptoms } \\
\text { are treated with intranasal } \\
\text { corticosteroids } \\
\text { Combination sprays (intranasal } \\
\text { corticosteroids with nasal } \\
\text { antihistamines) and short courses of } \\
\text { oral steroids for severe cases and/or } \\
\text { nasal polyps } \\
\text { Allergen immunotherapy is used } \\
\text { when a strong association with } \\
\text { allergens exists }\end{array}$ \\
\hline $\begin{array}{l}\text { Acute eosinophilic } \\
\text { pneumonia }\end{array}$ & $\begin{array}{l}\text { Idiopathic, hypothesized } \\
\text { to be a hypersensitivity } \\
\text { reaction } \\
\text { Temporal relation with } \\
\text { exposure to different } \\
\text { allergens/irritants, especially } \\
\text { tobacco smoke } \\
\text { Fever, dyspnea, and cough } \\
\text { Respiratory distress can } \\
\text { be present and progress to } \\
\text { respiratory failure }\end{array}$ & $\begin{array}{l}\text { Inspiratory crackles and } \\
\text { possible wheezes } \\
\text { Peripheral eosinophilia not } \\
\text { common } \\
\text { CXR: bilateral opacities } \\
\text { of alveolar, interstitial, or } \\
\text { mixed pattern } \\
>25 \% \text { eosinophils on BAL } \\
\text { or eosinophilic pneumonia } \\
\text { on lung biopsy } \\
\text { Absence of other causes of } \\
\text { pulmonary eosinophilia }\end{array}$ & $\begin{array}{l}\text { Responds well to corticosteroids } \\
\text { IV methylprednisolone } 125 \mathrm{mg} \\
\text { every } 6 \text { hours for initial dose } \\
\text { Switch to oral prednisone of } \\
40-60 \mathrm{mg} \text { daily once symptoms } \\
\text { improve } \\
\text { Taper over 2-6 weeks }\end{array}$ \\
\hline
\end{tabular}


Table 1. Summary of IgE related pulmonary conditions (Continued)

\begin{tabular}{|c|c|c|c|}
\hline Disease & Characteristics & Diagnosis & Treatment \\
\hline $\begin{array}{l}\text { Chronic } \\
\text { eosinophilic } \\
\text { pneumonia }\end{array}$ & $\begin{array}{l}\text { Insidious course } \\
\text { Eosinophilic infiltration } \\
\text { leads to tissue damage } \\
\text { Not associated with } \\
\text { environmental exposures } \\
\text { Productive cough, weight } \\
\text { loss, fever, night sweats, and } \\
\text { dyspnea }\end{array}$ & $\begin{array}{l}\text { Wheezes/crackles present } \\
\text { for more than } 2 \text { weeks } \\
\text { Alveolar eosinophilia } \\
\geq 40 \% \text { on BAL; blood } \\
\text { eosinophilia } \geq 1000 / \mu 1 \\
\text { CXR: Predominantly } \\
\text { peripheral pulmonary } \\
\text { infiltrates } \\
\text { Absence of other causes of } \\
\text { pulmonary eosinophilia }\end{array}$ & $\begin{array}{l}\text { High dose corticosteroids } \\
0.5 \mathrm{mg} / \mathrm{kg} \text { /day continued for } \\
2 \text { weeks after resolution of } \\
\text { symptoms and radiologic findings } \\
\text { Taper steroids to the lowest effective } \\
\text { dose to control the symptoms } \\
\text { High rate of relapse } \\
\text { Occasional need of long term } \\
\text { steroids } \\
\text { Steroid-sparing drugs: anti-IgE and } \\
\text { anti-IL-5 monoclonal antibodies }\end{array}$ \\
\hline $\begin{array}{l}\text { Parasitic lung } \\
\text { infections }\end{array}$ & $\begin{array}{l}\text { Hydatid cystic lung disease, } \\
\text { Amoebiasis, Ascariasis, } \\
\text { and Schistosomiasis cause } \\
\text { parasitic lung infections } \\
\text { Stimulate a TH2 response: } \\
\text { eosinophilia, IL-4, IL-5, IL- } \\
\text { 13, and antigen-specific IgE }\end{array}$ & $\begin{array}{l}\text { Travel history and exam are } \\
\text { paramount } \\
\text { CXR and CT are helpful } \\
\text { Amoebiasis: stool positive } \\
\text { for trophozoites and } \\
\text { serum positive for parasite } \\
\text { specific antibodies }\end{array}$ & $\begin{array}{l}\text { Hydatid cysts may require surgical } \\
\text { resection and albendazole } \\
\text { Amoebiasis is treated with } \\
\text { tinidazole or metronidazole for } \\
\text { trophozoites, then paromomycin for } \\
\text { intestinal cysts } \\
\text { Surgical treatment may be needed in } \\
\text { pleuropulmonary disease }\end{array}$ \\
\hline $\begin{array}{l}\text { Allergic } \\
\text { bronchopulmonary } \\
\text { aspergillosis }\end{array}$ & $\begin{array}{l}\text { Hypersensitivity reaction to } \\
\text { Aspergillus fumigatus } \\
\text { Commonly seen in cystic } \\
\text { fibrosis and asthma } \\
\text { Recurrent cough, wheezing, } \\
\text { pleuritic chest pain, } \\
\text { dyspnea, blood tinged } \\
\text { sputum, and brown mucus } \\
\text { plugs }\end{array}$ & $\begin{array}{l}\text { Supported by clinical } \\
\text { picture, radiological } \\
\text { findings, and immunologic } \\
\text { findings } \\
\text { Peripheral eosinophilia, } \\
\text { elevated total IgE (>1000 } \\
\text { IU/mL), and Aspergillus } \\
\text { specific IgE } \\
\text { Positive Aspergillus } \\
\text { intradermal skin testing } \\
\text { CXR: parenchymal } \\
\text { infiltrates and } \\
\text { bronchiectasis usually in } \\
\text { upper lobes, better defined } \\
\text { by HRCT }\end{array}$ & $\begin{array}{l}\text { Long-term corticosteroids: } \\
\text { prednisolone } 0.5-1 \mathrm{mg} / \mathrm{kg} / \text { day for } \\
2 \text { weeks, then } 0.5 \mathrm{mg} / \mathrm{kg} \text { every other } \\
\text { day for } 6-8 \text { weeks, then a slow taper } \\
\text { over } 3-5 \text { months } \\
\text { Itraconazole } 200 \mathrm{mg} \text { twice daily for } \\
16 \text { weeks } \\
\text { Omalizumab may be used as a } \\
\text { steroid sparing drug or adjunct } \\
\text { in patients who fail to respond to } \\
\text { steroids }\end{array}$ \\
\hline
\end{tabular}


but variable airflow obstruction that is often reversible either spontaneously or with treatment. The inflammation also causes an increase in bronchial hyperresponsiveness to a variety of stimuli. Reversibility of airflow limitation may be incomplete in some patients. Asthma was reported to affect 22 million people in the US in $2007 .^{3}$

Airflow limitation is the hallmark of asthma. It is usually caused by airway hyperresponsiveness, which is an exaggerated response to stimuli leading to bronchoconstriction. This can be allergen induced when antigen specific IgE crosslinks on the surface of mast cells and releases mediators (e.g., histamine, prostaglandins, leukotrienes, and tryptase) resulting in airway smooth muscle contraction. Patients with high levels of $\mathrm{IgE}$ are more likely to have asthma than those with normal IgE levels; however, there is no absolute cutoff for IgE levels in patients with asthma. Aspirin, NSAIDs, stress, exercise, irritants, and cold air can also stimulate bronchoconstriction but not through IgE mediated reactions. As the disease progresses, chronic inflammation develops, and this leads to airway edema characterized by mucus hypersecretion, inspissated mucus plugs, and hypertrophy of airway smooth muscles. Airway remodeling occurs as a consequence of chronic inflammation leading to non-reversible structural changes and partially reversible airflow limitation. Examples of this include thickening of the basement membrane, subepithelial fibrosis, mucus cell hyperplasia/hypertrophy, and blood vessel proliferation. ${ }^{3}$

In one study, the most common reported symptoms with asthma included chest tightness, wheezing, coughing, and shortness of breath. ${ }^{4}$ These symptoms are frequently episodic and related to exposure to triggers and typically resolve spontaneously or with medications. Symptoms can increase at night causing nighttime awakenings. Physical examination findings are not specific for asthma. Suggestive findings include wheezing on normal or forced expiration, increased nasal secretions, nasal mucosal inflammation, nasal polyposis, and eczema. ${ }^{3}$

After a diagnosis of asthma is considered, pulmonary function tests measuring FEV1, FVC, and FEV1/FVC before and after bronchodilator should be ordered. These tests should show a reduced FEV1 and reduced FEV1/FVC in patients with asthma, which suggests obstruction. Reversibility is present when FEV1 (or FVC) increases by $\geq 12 \%$ or $>200 \mathrm{ml}$ after bronchodilator administration. The presence of a consistent history and symptoms, obstructive PFTs, and the exclusion of other possible diagnoses are generally adequate to make a diagnosis of asthma. ${ }^{3}$ When patients present with symptoms strongly suggesting asthma but have normal PFTs, provocation tests using methacholine, histamine, or exercise can be done. Further workup could include skin testing to evaluate for environmental triggers of asthma. ${ }^{3}$

After the diagnosis is made, asthma severity should be assessed by checking symptom severity, effect on daily activities, nighttime awakenings, impact on quality of life, and lung function with PFTs. ${ }^{3}$ Treatment of asthma requires avoidance of triggers, control of symptoms with medications, and prompt recognition and treatment of complications. A stepwise approach to treatment is recommended. Short acting beta agonists are used as needed initially. Inhaled corticosteroids are the cornerstone for maintenance therapy, and long acting beta agonists are added later if control is inadequate. Leukotriene receptor antagonists can reduce symptoms in both upper and lower airways. Specific allergen immunotherapy can be used in cases in which a strong association between the asthma syndrome and an allergen is apparent. $^{3}$

Immunomodulators in asthma are a current area of clinical study. Interleukins are glycoproteins produced by lymphocytes to regulate immune responses and are targeted in asthma therapy. The first approved modulator was omalizumab (anti-lgE) for use in moderate to severe asthma. Mepolizumab (anti-IL-5), reslizumab (anti-IL-5), benralizumab (antiIL-5R $\alpha$ ), and dupilumab (anti-IL-4R $\alpha$ ) are all newer immunomodulators that have been approved for use in patients with moderate and/or severe asthma. ${ }^{5}$

\section{Allergic RHINITIS}

Allergic rhinitis (AR) is a chronic inflammatory disorder of the nasal mucosa that involves both early 
and late hypersensitivity reactions. It affects about 400 million people worldwide yearly. ${ }^{6}$ Allergic rhinitis is associated with other chronic inflammatory conditions, including asthma, rhinosinusitis, and allergic conjunctivitis. It has a major impact on quality of life, including sleep, productivity, and social life. ${ }^{7}$ Since AR is a prevalent disease, it produces a significant financial burden, estimated at $\$ 11.2$ billion in $2005 .^{8}$

$\lg E$ has a major role in the pathogenesis of AR. However, in patients with perennial allergic rhinitis, total IgE levels do not correlate with skin test reactivity. Within minutes of exposure to inhaled allergens, like pollen, mold, dust mites, or animal dander, crosslinking of $\mathrm{IgE}$ on the surface of mast cells occurs. This leads to the release of inflammatory mediators, including histamine, prostaglandins, and leukotrienes, which are responsible for the early phase of the allergic reaction. The late phase is mediated by other inflammatory cells, namely neutrophils, eosinophils, and T lymphocytes, that are activated by the same mediators. This typically occurs hours after the exposure to the allergen. ${ }^{7}$

Common symptoms of the early phase of AR include congestion, rhinorrhea, sneezing, itching, upper airway obstruction, and watery eyes. Late phase symptoms are related to chronic inflammation, and nasal congestion is the most common complaint. ${ }^{7}$ Allergic rhinitis is usually seasonal but can be persistent when caused by non-seasonal allergens, like dust mites, animal dander, or mold. ${ }^{9}$

A comprehensive history and physical examination are usually sufficient to make the diagnosis of AR and initiate therapy. Historical details should include chronicity, seasonality, and pattern of symptoms. A detailed environmental history and occupational exposure history are essential in identifying precipitating factors. Physical examination should include systems that could be affected in AR, such as skin, upper airways, lower airways, and gastrointestinal tract. Treatment can be started based on a supportive history and examination. It is not always necessary to perform allergen specific IgE testing, but identifying culprit allergens is associated with better patient outcomes, probably secondary to avoidance and targeted immunotherapy. ${ }^{10}$
Mild or episodic symptoms are managed on an as needed basis using oral second-generation antihistamines or intranasal corticosteroids. For patients with moderate to severe symptoms, regular use of intranasal corticosteroids effectively reduces symptoms. Combination sprays (intranasal steroids with antihistamines) and leukotriene receptor antagonists may be needed for better control. Short courses of oral corticosteroids (5-7 days) are used in severe intractable cases or to treat nasal polyposis. ${ }^{9}$ Intranasal anticholinergic nasal sprays reduce rhinorrhea/postnasal drip; while anti-leukotriene inhibitors provide symptomatic relief similar to antihistamines. ${ }^{11}$ Omalizumab has been proven effective in alleviating symptoms of AR but is not approved for that use. ${ }^{9}$ Anti-IL-5 therapy is also being evaluated in patients with $A R$ and nasal polyps. $^{12}$

Allergen immunotherapy was effective in the treatment of AR in several studies. ${ }^{9}$ Subcutaneous immunotherapy is widely used in severe, intractable cases in which medical therapy and avoidance of allergens have not achieved adequate control and/or the patient wants to take less medication.

\section{ACUTE EOSINOPHILIC PNEUMONIA}

Eosinophilic pneumonia was originally thought to have a chronic course. Acute eosinophilic pneumonia was first described in 1989 when a patient presented with acute respiratory distress and bilateral pulmonary infiltrates. ${ }^{13}$ After ruling out an infectious etiology, the bronchoalveolar lavage (BAL) and transbronchial biopsy confirmed the presence of an eosinophilic infiltrate. This patient responded well to corticosteroid therapy.

Acute eosinophilic pneumonia (AEP) is thought to have no single cause. Some authors hypothesized that it is a hypersensitivity reaction in the lungs. This belief is due to the temporal relationship between the onset of AEP and recent exposure to different allergens. Tobacco smoking has been the most frequently identified exposure associated with AEP; other potential exposures associated with AEP are summarized in Table $2 .{ }^{14} \mathrm{TH} 2$ cells have a major role in the pathogenesis of AEP; high levels of IL-5 and IL-18 are found 
Table 2. Exposures reported to be associated with AEP

\begin{tabular}{|l|}
\hline Drugs \\
- Minocycline \\
- Fludarabine \\
- Sertraline \\
- Intramuscular progesterone \\
- BCG vaccine \\
\hline Inhalation exposure \\
- Tobacco smoke \\
- Forld Trade Center demolition dust \\
- Tear gas bomb explosion \\
- Cave exploration \\
- Plant repotting \\
\hline
\end{tabular}

in the BAL fluid of patients with AEP. These cytokines recruit large numbers of eosinophils into the alveoli and interstitium and activate them to release their granules leading to the lung damage seen in AEP. ${ }^{14}$

Patients typically present with fever, dyspnea, and cough. They have variable degrees of respiratory distress that can progress to respiratory failure requiring intubation, but this has been rarely reported. ${ }^{15}$ Pulmonary examination reveals inspiratory crackles and rarely wheezing. ${ }^{14}$ Complete blood counts, a comprehensive metabolic panel, and liver function testing should be done, but no laboratory tests are specific for AEP. Peripheral eosinophilia is not ordinarily present. ${ }^{14}$ Arterial blood gas will reveal hypoxemia of variable degrees; the $\mathrm{PaO}_{2}$ is $<60 \mathrm{~mm} \mathrm{Hg}$. The chest $\mathrm{x}$-ray (CXR) shows bilateral opacities in an alveolar, interstitial, or mixed pattern. ${ }^{15}$

A case series of 5 patients presenting with AEP and transient wheezes reported levels of $\mathrm{IgE}$ ranging from 106-2,310 U/ml (normal: 0-300 U/ml). Pulmonary function tests showed irreversible small airway dysfunction, and biopsies showed eosinophilic infiltration into bronchial mucosa and the epithelium of the bronchioles. This demonstrates that eosinophilic infiltration is not limited to the lung parenchyma as previously believed. Eosinophilic bronchitis can be present in AEP, and these patients commonly have wheezing on examination. ${ }^{16}$ These are the only cases with elevated IgE levels associated with AEP, and its role in the disease pathogenesis has not been well studied.

Diagnostic criteria were adopted to help diagnose AEP without the need for lung biopsy. The criteria require all the following: ${ }^{17}$

1. Acute onset of respiratory symptoms with fever manifestations for less than 1 month in duration

2. Bilateral diffuse infiltrates on chest radiograph

3. Hypoxemia defined as $\mathrm{PaO}_{2}<60 \mathrm{~mm} \mathrm{Hg}$ or arterial oxygen saturation $<90 \%$ on room-air pulse oximetry

4. BAL $>25 \%$ eosinophils or eosinophilic pneumonia on lung biopsy

5. Absence of known causes of pulmonary eosinophilia, including drugs, toxins, and infections.

Corticosteroids are the main treatment, and varying doses have been reported in the literature. Intravenous methylprednisolone (125 mg every 6 hours) is often the initial dose. Rapid improvement generally occurs, and the patient can be switched to oral prednisone at 40-60 mg daily which can then be tapered over 2-6 weeks. ${ }^{18}$ A study comparing a 2 or 4-week taper of corticosteroids reported no added benefit for the 4-week period. ${ }^{19}$ These patients typically have complete recovery and no residual respiratory symptoms, and no relapses have been reported after corticosteroids are stopped.

\section{ChRONIC EOSINOPHILIC PNEUMONIA}

Chronic eosinophilic pneumonia (CEP) was first described in 1969 by Charles Carrington when 9 women presented with high fever, night sweats, weight loss, and severe dyspnea. ${ }^{20}$ They were initially treated for tuberculosis with no improvement. Eventually, they had lung biopsies demonstrating eosinophilic infiltration and responded dramatically to corticosteroids.

Chronic eosinophilic pneumonia, unlike AEP, is an insidious disease, and it often takes months before a clinical diagnosis is made. It is characterized 
by eosinophilic infiltration leading to tissue damage. It is a rare disease with a reported incidence of $0.23 / 100,000$ population ${ }^{21}$ and occurs mostly in females. Chronic eosinophilic pneumonia doesn't spontaneously resolve and can cause irreversible pulmonary fibrosis if untreated..$^{22}$

Like AEP, TH2 cells have an integral role in the pathogenesis of the CEP. These cells release IL-5, which recruits and activates eosinophils. The release of proteolytic material from eosinophilic granules leads to tissue damage. High levels of IL-5, IL-6, IL-10, and eosinophils are found in the BAL of affected patients. ${ }^{23}$ The initiating stimulus is unknown, and smoking and environmental factors are not associated with CEP. IgE levels were elevated in approximately one half of the patients in a study involving 62 cases. Most of these patients had an atopic history, so it was not clear whether the elevated IgE was related to CEP or to coexisting atopic conditions. ${ }^{24}$

These patients present with productive cough, fever, weight loss, night sweats, and dyspnea. Hemoptysis and chest pain can occur but are rare. Pulmonary examination reveals wheezes and/or crackles. It is a slowly progressive disease, and the patients do not necessarily appear ill. ${ }^{22}$ No specific laboratory testing is available for CEP. Complete blood counts with differential counts, comprehensive metabolic panel, erythrocyte sedimentation rate (ESR), C-reactive protein (CRP), and arterial blood gases should be done. Blood eosinophils are typically elevated $(>1,000 / \mu \mathrm{L})$. As mentioned previously, lgE is elevated in one half of the cases. The other tests are non-specific and include elevated ESR, CRP, and platelet counts. ${ }^{22}$

Chest imaging is essential in the diagnosis of CEP. These patients frequently have bilateral peripheral parenchymal infiltrates which are described as the photographic negative of pulmonary edema. However, this pattern is present in only $25 \%$ of cases and is not specific. The infiltrates commonly have an alveolar pattern ranging from ground glass to consolidation with air bronchograms and can be migratory. ${ }^{22}$ Since the patients do not respond to conventional treatment, bronchoscopy is done to rule out infection. The BAL has an elevated eosinophil count that is always higher than $25 \% .^{22}$
Diagnostic criteria proposed for the CEP include: ${ }^{25}$

1. Respiratory symptoms for more than 2 weeks

2. Alveolar and/or blood eosinophilia (alveolar eosinophilia $\geq 40 \%$ at BAL differential cell count; blood eosinophilia $\geq 1000 / \mu \mathrm{l}$ )

3. Pulmonary infiltrates with a peripheral predominance on chest imaging

4. Exclusion of any known cause of eosinophilic lung disease.

A surgical lung biopsy is not always needed for the diagnosis. If the BAL fluid shows no eosinophilia, but the suspicion for CEP is high, a surgical lung biopsy could help confirm the diagnosis. Pathology shows alveolar eosinophils and histiocytes; minimal fibrosis is seen early in the course of the disease. ${ }^{22}$

After the diagnosis is made, treatment should be started immediately to reduce symptoms and prevent irreversible fibrosis. The main treatment is high dose corticosteroids. Oral prednisone at doses of $0.5 \mathrm{mg} /$ $\mathrm{kg} /$ day is effective and is continued for 2 weeks after resolution of symptoms and radiologic abnormalities. A small percent of patients may present with fulminant rapidly progressive disease and should be started on high dose IV methylprednisolone ( $250 \mathrm{mg}$ every 6 hours) in the initial phase. The dose of corticosteroids should be tapered to the lowest effective dose to control the symptoms. Unlike AEP, CEP has a high rate of relapse after discontinuation of steroids. The duration of therapy isn't well studied with some patients staying on low dose prednisone (5-10 mg daily) indefinitely. ${ }^{22}$

A study comparing initial treatment with prednisone $(0.5 \mathrm{mg} / \mathrm{kg} /$ day $)$ for 3 months (taper by $20 \%$ every 2 weeks) vs 6 months (tapered by $20 \%$ every 2 weeks for 2 months followed by $20 \%$ every 3 weeks) was done comparing rates of relapse. ${ }^{26}$ These study arms had similar outcomes with no added benefit with the prolonged treatment period.

Since long-term glucocorticoid therapy is associated with several side effects, corticosteroid sparing medications may be needed. Inhaled glucocorticoid can reduce the dose of systemic corticosteroids 
during acute flares but should not be used alone. Anti-IgE, omalizumab, and new IL-5 inhibitors, such as benralizumab, mepolizumab, and reslizumab, provide some benefit in patients with CEP, especially in patients with concomitant asthma and positive allergy tests. ${ }^{22}$

\section{Parasitic lung infections}

The incidence of parasitic lung infections is increasing due to worldwide travel and migration. These infections occur in both immunocompetent and immunocompromised hosts. Parasites stimulate a $\mathrm{TH} 2$ response involving IL-4, IL-5, IL-13, eosinophilia, and eventually class switching to produce antigen specific $\lg E$. The cross-linking of IgE on the surface of basophils, eosinophils, and mast cells by the parasitic antigens leads to release of preformed proteases and toxic proteins that are necessary to control different stages of the helminthic infections. ${ }^{27}$

Hydatid cystic lung disease is caused by the species Echinococcus granulosus. This parasite is present in dogs' guts and is transferred to humans through feces contaminated food. The eggs hatch producing larvae that travel through the circulation to reach the liver and the lungs where they develop slowly into hydatid cysts. The cysts can remain asymptomatic for years before incidentally being found on imaging. Symptoms include cough, hemoptysis, or chest pain. The diagnosis is often made with radiology examination. On chest $\mathrm{x}$-ray, cysts are well-defined lesions surrounded by normal lung parenchyma. Computed tomography of the chest shows more detailed features, including presence of daughter cysts or cyst rupture. ${ }^{28}$ Laboratory testing is non-specific, and serologic testing is not sensitive for lung disease. Treatment usually requires surgical resection of the cyst. Postoperative albendazole can be used, but treatment should be avoided preoperatively due to potential weakening of the cyst wall that can lead to rupture causing an anaphylactic reaction. ${ }^{29}$

Amoebiasis is caused by Entamoeba histolytica. The trophozoite form of the parasite lives in the intestinal lumen where they multiply and differentiate into cysts. These cysts are passed in feces and are spread by the fecal-oral route. In most carriers the trophozoites do not invade the gut lining, but in some cases the trophozoite attaches to the gut mucosa causing lysis of the epithelium. This leads to invasive amoebiasis and colitis. Hematogenous spread of trophozoites can cause the formation of amoebic liver abscesses. Amoebic pleuropulmonary disease occurs in about $15 \%$ of patients with amoebic liver abscess and develops by direct extension into the lung parenchyma causing pneumonia or lung abscesses. Empyema can also occur after rupture of a hepatic abscess with direct extension into the pleural space. Patients present with cough with fever, sputum production, pleuritic pain, and dyspnea. Chest $\mathrm{x}$-rays typically show right lower lobe disease, including pleural effusion and consolidation. Laboratory testing includes stool studies for trophozoites which are not usually present in sputum or pleural fluid. Antibodies against the parasite can also be detected in the serum. Treatment involve tinidazole or metronidazole to kill trophozoites followed by paromomycin to destroy intestinal cysts. Surgical treatment is sometimes needed in pleuropulmonary disease. ${ }^{29}$

Other parasites are associated with lung disease. These include Ascaris lumbricoides, Toxocara canis, Schistosoma, and others and are discussed in an excellent review article by Kunst et al. ${ }^{29}$

\section{Allergic bronchopulmonary aspergillosis}

Allergic bronchopulmonary aspergillosis (ABPA) occurs when the airways are colonized by Aspergillus fumigatus. Hypersensitivity reactions to Aspergillus antigens lead to the development of symptoms. ${ }^{30}$ This disease frequently occurs in patients with cystic fibrosis and severe asthma, and prevalences as high as $9 \%$ and $13 \%$ have been reported in asthma and cystic fibrosis, respectively. ${ }^{31}$ In immunocompetent individuals, colonization of lower airways by Aspergillus spp. is common but rarely has any clinical significance. However, in immunocompromised patients, colonization can lead to clinical symptoms and ABPA. ${ }^{32}$

Helper T cells are the main cells associated with the pathogenesis of this hypersensitivity response. They are activated by the antigens of the fungus leading to 
production of IgE, eosinophilia, and mast cell degranulation. Proinflammatory cytokines IL-4, IL-5, IL-8, and IL-13 are produced which damage the epithelial cells and increase blood and airway $\operatorname{lgE}{ }^{30}$ Chronic bronchial inflammation, eosinophilia, airways remodeling, and bronchiectasis are seen in lung histology. ${ }^{30}$

The clinical presentation varies; these patients present with non-specific symptoms, including low grade fever, weight loss, anorexia, malaise, and fatigue. Recurrent wheezing, cough, dyspnea, blood stained mucus, or brown mucus plugs are also common presentations. ${ }^{30}$

The diagnosis of ABPA requires typical clinical features, radiological signs, and immunologic findings. The CXR shows pulmonary infiltrates and bronchiectasis often in the upper lobes. These changes can be further characterized with high resolution computed tomography (HRCT). Patients with no abnormalities on HRCT have been reported. ${ }^{30}$ Aspergillus skin testing is done to confirm immediate hypersensitivity to Aspergillus. Positive tests signify the presence of Aspergillus fumigatus specific IgE. Peripheral eosinophilia, Aspergillus specific IgE, and total serum $\mathrm{IgE}$ are frequently elevated above $1,000 \mathrm{IU} / \mathrm{mL}$ (normal: 0-300 U/ml). ${ }^{30}$

Treatment goals include controlling inflammation and maintaining normal lung function. Corticosteroids are the primary treatment during acute exacerbations. Prednisone is used (dose of $0.5-1 \mathrm{mg} / \mathrm{kg} /$ day) for 2 weeks followed by $0.5 \mathrm{mg} / \mathrm{kg}$ every other day for an additional $6-8$ weeks. This is followed by a slow taper over 3-5 months. A low dose maintenance regimen (5-10 mg daily) can be used long term to avoid exacerbations and maintain remission. IgE levels are usually checked every 2 months after an acute exacerbation to ensure response to treatment. Inhaled corticosteroids can decrease the dose of systemic corticosteroids. ${ }^{30}$

Antifungals, mainly itraconazole, are used to reduce the fungal load and associated inflammation. The dose recommended is $200 \mathrm{mg}$ twice daily for 16 weeks; this often leads to significant reductions in the corticosteroid dose needed to control the disease. Finally, omalizumab is used as steroid sparing medication or alternative to decrease exacerbations and improve symptoms. This is especially important in patients with uncontrolled asthma. ${ }^{30}$

Eosinophilic granulomatosis with polyangiitis is reviewed in Part 1 of the review Immunoglobulin E associated systemic conditions. ${ }^{33}$

\section{SUMmARY}

Several pulmonary diseases have $\operatorname{lgE}$ as an important factor in their etiology. More complete understanding of its function and structure has enabled clinicians to better manage these disorders. With the emergence of new medications designed to inhibit the production or activity of $\lg \mathrm{E}$, better control of these diseases has become possible. Additional advances in treatment are expected as more targeted and less toxic medications are being developed.

Article citation: Ismail A, Iwuji KC, Tarbox JA. Immunoglobulin $\mathrm{E}$ associated respiratory diseases:

Part 2. The Southwest Respiratory and Critical Care Chronicles 2019;7(31):34-43

From: Department of Internal Medicine, Texas Tech University Health Sciences Center, Lubbock, Texas

Submitted: 9/24/2019

Accepted: 10/19/2019

Reviewer: John Pixley MD

Conflicts of interest: none

This work is licensed under a Creative Commons Attribution-ShareAlike 4.0 International License.

\section{REFERENCES}

1. Oettgen HC. Fifty years later: Emerging functions of $\operatorname{IgE}$ antibodies in host defense, immune regulation, and allergic diseases. J Allergy Clin Immunol 2016;137(6):1631-1645.

2. Ishizaka T, Ishizaka, $K$, Johansson, $S$, et al. Histamine release from human leukocytes by anti-e antibodies. Immunol 1969 102(4):884-892.

3. National Asthma Education and Prevention Program: Expert panel report III: Guidelines for the diagnosis and management of asthma. Bethesda, MD: National Heart, Lung, and Blood Institute, 2007. (NIH publication no. 08-4051) www. nhlbi.nih.gov/guidelines/asthma/asthgdln.htm (Accessed on June 03, 2018). 
4. Globe G, Martin M, Schatz M, et al. Symptoms and markers of symptom severity in asthma-content validity of the asthma symptom diary. Health Qual Life Outcomes 2015;13:21.

5. Kim AS, Doherty TA. New and emerging therapies for asthma. Ann Allergy Asthma Immunol. 2016;116(1):14-17.

6. Greiner AN, Hellings PW, Rotiroti G, et al. Allergic rhinitis. The Lancet 2011 Dec 17; 378(9809):2112-22.

7. May JR, Dolen WK. Management of allergic rhinitis: a review for the community pharmacist. Clin Ther 2017 Dec; 39(12):2410-2419.

8. Hay JW, Kaliner MA. Costs of second-generation antihistamines in the treatment of allergic rhinitis: US perspective. Curr Med Res Opin 2009;25:1421-1431.

9. Wallace DV, Dykewicz MS, Bernstein DI, et al. The diagnosis and management of rhinitis: an updated practice parameter. J Allergy Clin Immunol 2008;122 (Supp1): S1-S84.

10. Szeinbach SL, Williams PB, Kucukarslan S, et al. Influence of patient care provider on patient health outcomes in allergic rhinitis. Ann Allergy Asthma Immunol 2005;95:167.

11. Lagos JA, Marshall GD. Montelukast in the management of allergic rhinitis. Ther Clin Risk Manag 2007;3(2):327-332.

12. Avdeeva K, Fokkens W. Precision medicine in chronic rhinosinusitis with nasal polyps. Curr Allergy Asthma Rep 2018; 18(4):25.

13. Badesch DB, King TE Jr, Schwarz MI. Acute eosinophilic pneumonia: a hypersensitivity phenomenon? Am Rev Respir Dis 1989; $139: 249$.

14. Allen J. Acute eosinophilic pneumonia. Semin Respir Crit Care Med 2006;27:142.

15. Janz DR, O’Neal HR Jr, Ely EW. Acute eosinophilic pneumonia: A case report and review of the literature. Crit Care Med 2009;37:1470.

16. Ogawa H, Fujimura M, Matsuda $T$, et al. Transient wheeze: eosinophilic bronchiolitis in acute eosinophilic pneumonia. Chest 1993;104:493-496.

17. Philit F, Etienne-Mastroïanni B, Parrot A, et al. Idiopathic acute eosinophilic pneumonia: A study of 22 patients. Am J Respir Crit Care Med 2002;166:1235-1239.

18. Jantz MA, Sahn SA. Corticosteroids in acute respiratory failure. Am J Respir Crit Care Med 1999;160:1079-1100.

19. Rhee CK, Min KH, Yim NY, et al. Clinical characteristics and corticosteroid treatment of acute eosinophilic pneumonia. Eur Resp J 2013 41:402-409.
20. Carrington $\mathrm{CB}$, Addington WW, Goff AM, et al. Chronic eosinophilic pneumonia. N Eng J Med 1969;280:787-798.

21. Sveinsson OA, Isaksson HJ, Gudmundsson G. Chronic eosinophilic pneumonia in Iceland: clinical features, epidemiology and review. Laeknabladid 2007;93:pp. 111-114.

22. Allen J, Wert M, Eosinophilic Pneumonias. J Allergy Clin Immunol Pract 2018 Sep - Oct;6(5):1455-1461.

23. Alam M, Nausherwan KB. Chronic eosinophilic pneumonia: a review. South Med J 2007;100:pp. 48-53.

24. Marchand E, Reynaud-Gaubert M, Lauque D, et al. Idiopathic chronic eosinophilic pneumonia. A clinical and followup study of 62 cases. Medicine (Baltimore) 1998;77:299312 .

25. Marchand E, Cordier JF. Idiopathic chronic eosinophilic pneumonia. Orphanet J Rare Dis 2006;1:11. doi:10.1186/17501172-1-11.

26. Suzuki Y, Suda T. Long-term management and persistent impairment of pulmonary function in chronic eosinophilic pneumonia: A review of the previous literature. Allergol Int 2018 Jul;67(3):334-340.

27. Fitzsimmons CM, Falcone FH, Dunne DW. Helminth allergens, parasite-specific IgE, and its protective role in human immunity. Front Immunol 2014;5:61.

28. Erdem CZ, Erdem LO. Radiological characteristics of pulmonary hydatid disease in children: less common radiological appearances. Eur J Radiol 2003;45:123e8.

29. Kunst H, Mack D, Kon OM, et al. Parasitic infections of the lung: a guide for the respiratory physician. Thorax 2011;66:528-536.

30. Sisodia J, Bajaj T. Allergic Bronchopulmonary aspergillosis (ABPA) [Updated 2019 Jul 29]. In: StatPearls [Internet]. Treasure Island (FL): StatPearls Publishing; 2019 Jan.

31. Agarwal R, Sehgal IS, Dhooria S, et al. Developments in the diagnosis and treatment of allergic bronchopulmonary aspergillosis. Expert Rev Respir Med 2016 Dec;10(12):13171334.

32. Gago S, Denning DW, Bowyer P. Pathophysiological aspects of Aspergillus colonization in disease. Med Mycol 2019 Apr 01;57.

33. Ismail A, Iwuji KC, Tarbox JA. Immunoglobulin E associated systemic conditions. The Southwest Respiratory and Critical Care Chronicles 2019;7(30):29-35. 